\title{
Assessment and optimization of economic restructuring in a small peripheral region
}

\author{
MARKKU TYKKYLÄINEN
}

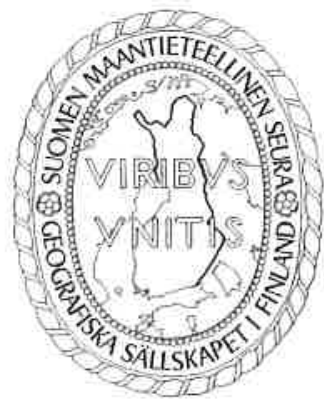

Tykkyläinen, Markku (1990). Assessment and optimization of economic restructuring in a small peripheral region. Fennia 168:1, pp. 117-136. Helsinki. ISSN 0015-0010.

An evaluation model is presented which is suitable for planning methods related to the construction of regional economic scenarios. The model is constructed for assessment and optimization the regional economic structure in the medium-run. A scenario experiment was performed in a small peripheral area of Finland, Northern Karelia, in the early 1980s, and preliminary results are given regarding its ability to evaluate the course of restructuring in manufacturing in this area. The best estimates of restructuring were provided by selected individuals forming expert groups, and the best fit at this stage is achieved by the scenario representing the majority of those questioned. The optimization procedure proved to be fruitful only for finding the constraints on the possible economic development paths. The base year for the model was 1978 and the essential criterion parameters, the profitability estimates, were from the years 1974 79. These profitability parameters had changed only slightly by 1984 and 1985, so that the results remain applicable to the mid- 80 s and indicate that this course of the restructuring is a more permanent phenomenon.

Markku Tykkyläinen, University of Joensuu, P.O. Box 111, SF-80101 Joensuu, Finland. MS received 4th December, 1989 (revised 14th January, 1990).

\section{Aims and starting points}

Analysis and evaluation of a regional economic system by means of regional economic models is an extension of the use of practical tools in regional development planning. The model approach is needed when evaluating regional economic restructuring, for example, or for forecasting purposes or the evaluation of planning strategies.

Recent discussion of the aims and structure of such models and interpretation of their results has served to point out long-term problems in policymaking and the importance of a bottom-up approach and of qualitative policy recommendations in the form of general guidelines rather than straightforward quantitative results (see Snickars et al. 1982). This argumentation is well-founded in an environment of economic change and restructuring in which provision for new economic phenomena and changes in regional economic policy are distinctive features. Thus paths of possible development and future visions seem to constitute a relevant context for designing regional economic development. From the point of view of planning theory it is essential to evaluate different methods and their usefulness for practical planning purposes. Two main points are analyzed in this paper on the basis of empirical testing. Firstly, what are the chances of optimization and assessment for evaluating forthcoming regional economic restructuring, and secondly, how should they be carried out, and what are the capabilities of different planning teams for making such an evaluation?

The evaluation model presented here models certain basic variables of regional industrial development in order to describe with sufficient accuracy the outcomes of different alternative regional economic strategies. It writes out a set of pre-scenarios, or alternatives describing the state of the economy under certain assumptions. The possible future space for manoeuvre is limited by constraints and prerequisites (e.g. capital needs, power inputs etc.), and the state reached is evaluated in terms of the outcomes predicted by the model. The results are intended to be preliminary in the sense that there are some additional conditions such as technological advance, for example, which have to be taken into account when presenting the scenarios. The concept of scenario is used in this paper in a sense which includes pre-scenarios, i.e. outlines produced by the model for the purpose of scenario writing. Although designed in the first place for regional development 
planning, the model can be applied at different areal levels. The approach and the model were tested at the provincial level in Northern Karelia in eastern Finland. The scenarios were created in the early 1980 s when no opportunity existed for evaluating the appropriateness of the results (Tykkyläinen 1988), and they are now interpreted in this paper in order to evaluate the applicability of the model for planning purposes. Where the model has provided guidelines for regional economic development, the point of issue is what is the reliability and applicability of these visions and what is the mutual relationship between the different methods used in the evaluation model approach.

The framework for the evaluation aimed at creating alternative regional economic structures and outcomes is set out in a block diagram in which the blocks depict different factors and the arrows denote the main effects (Fig. 1). The evaluation design phase provides the starting point, at which different strategies of development can be chosen based on expectations regarding general economic development and restructuring and on the policy goals which have been set. These strategies are inserted into the model by means of constraints and employment targets, and by choosing between optimization and assessment.

The trends and expectations for economic development and the national and regional policies mentioned at the top of the diagram set the limits for feasible solutions (Fig. 1). In the evaluation design phase the conditions of the experiment are planned, taking into account the goals, available policy measures and expected market and cost conditions. The phase includes design of the evaluation routine, selection of optimization and/or simulation, design of constraints, selection of possible evaluation groups for performing the assessment etc. In the case of Northern Karelia the evaluation was made in 1983, when the old Provincial Development Plan was still in force (LAKS 1978), the time horizon was set at $10-15$ years, and both optimization and simulation were used.

The constraints are expressed down the righthand side of the diagram (Fig. 1). Labour, capital and production constraints proved to be the most important ones in the Northern Karelian study. The sectoral constraints imposed on resource processing industries by the extent of the natural resources and the pollution constraints may be essential in a complex industrial environment, but in the present case no modelling was needed because natural resources and environmental problems played only minor or even a decreasing role in most instances. Some calculations describing the limits of sectoral growth were made before the model was run and these results were applied in the evaluation design phase.

The output of the evaluation model is the set of figures describing labour force, wages and salaries, profits, capital requirements, number of establishments and gross values in the mining industry, manufacturing and power and water supplies. These figures are compared with the base year, providing results that are available for comparison with the regional development goals. Such indicators as resource use and waste output were intended for inclusion in the model at the preliminary stage but at the final stage, after analysis of the economicecological input-output model and establishment of the regional comparisons, this part of the model was not implemented (Tykkyläinen 1988).

The feedback arrows show that the results of the evaluation can be a continuous process, i.e. the conditions and constraints can be altered in order to generate further results based on experiences obtained in the use of the system. In some cases they can also lead to revision of the goals of regional economic planning. Delayed feedback refers to the effect of the planning on goals, regional policy and eventually the regional economy itself after the measures have been carried in practice.

\section{Structure of the model}

The evaluation model is composed of a simulation and a linear programming (LP) model which together describe the structure of the manufacturing and allied industries (SIC industry class codes $2-4$ ) in the region, including hypothetical industries operating using national production technology. The LP model can optionally be employed for optimization purposes and the simulation model, independently or together with the LP model, for analysis of the effects of the hypothetical development alternatives and regional development planning strategies attached to the scenarios.

The model was constructed in the early 1980s and the empirical material was taken from the year 1978 and the period $1974-79$ (Tykkyläinen 1988: 351— 353). The present analysis, based on that report, is also restricted to the manufacturing and allied industries (SIC 2-4), excluding agriculture, forestry and the service sector. The data concerning power and water consumption are included as far as the production sectors and the household sector are concerned, but the influence of agriculture, forestry, the service sector and households on water and power consumption in each scenario is assumed to be at the level which prevailed in 1978. Agriculture and especially forestry are included in the evaluation 


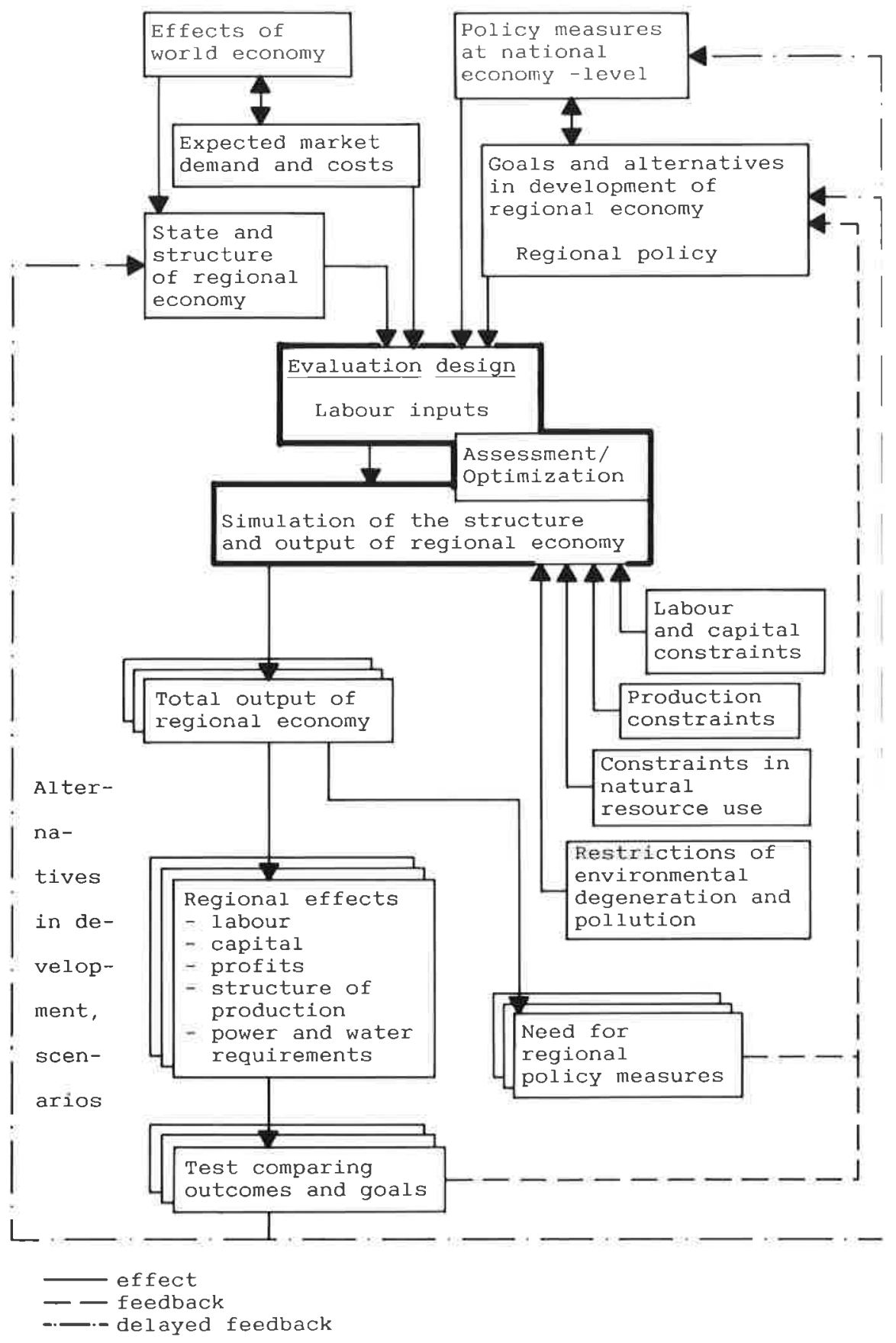

Fig. 1. An outline of the evaluation model. 
model as sectors providing a supply of natural resources, the extent of which forms the probable limiting factors for the expansion of the regional economy. This solution seems to be sufficient in view of the characteristics of the region studied, namely the decline in primary sector employment and the expansion of the service sector in accordance with national and local government policy, and no appreciable changes in population were expected. Thus the manufacturing industries represented the main instruments for regional growth and development, as they still are in Finnish regional policy at the present time.

When choosing industries based on data regarding the region itself and the whole of Finland, two types of production technology are available for optimization and simulation purposes: 1) technology native to Northern Karelia (industries 1-21), and 2) national technology, industries 22-48. It is possible to choose either or both.

The optimization part of the evaluation model, the LP model, contains 48 industries related to manufacturing and mining, 21 of which existed in the region in the $1970 \mathrm{~s}$, the rest being found nationally. Among the industries representing national technology, the mining sector, petroleum refineries and miscellaneous petroleum and coal products are rejected as being unsuitable for the region studied. The simulation model includes power (s) and water (w) supplies in addition to these 48 industries, the former consisting of the production of electricity, gas and heat. The number of industries in the model could be larger or smaller than the 50 included here, with corresponding adjustments in the sizes of the vectors. Thus the vector size was 62 elements at the construction phase but only $50(=48+\mathrm{s}+\mathrm{w})$ in the present application phase.

The criterion for profitability is the net rate a(i) of returns, calculated by means of following equation:

$$
a(i)=(j(i)-w(i)-d(i)) / x(i),
$$

in which $j(i)=$ value added in industry $i$ $w(i)=$ wages and salaries in industry $i$ $\mathrm{d}(\mathrm{i})=$ depreciation in industry $\mathrm{i}$, and $x(i)=$ total output of industry $i$.

The values for $\mathrm{d}(\mathrm{i})$ are calculated by recording all machinery and vehicles at $15 \%$ of their fixed capital value and all buildings at $5 \%$.

The figures used in the present model are arithmetical means of the net rates of returns over the six years 1974-79, based on published and unpublished industrial statistics. More sophisticated estimation methods could be employed, of course, but arithmetical means seem to be sufficiently valid for simulation purposes, and especially if the model is to be used by the development planning organizations, so that the method must be simple enough to be used in practice.

A comparison with other studies of profitability was made at the design phase, and the validity of the net rates of returns was tested. Alternative measures would be the gross rate of returns and the net gain on fixed capital. The former, to be denoted b(i), shows the economic outcome in relation to the total output without any allowances for depreciation: $b(i)=(j(i)-w(i)) / x(i)$, the correlation between the net and gross rates being .70 (Tykkyläinen 1988: 351 ). It thus seems possible to employ either gross rates of returns or net rates as estimates of profitability in scenario-type analyses without any major problems of accuracy. The intention at first was to use the net gains on fixed capital as the profitability coefficients and the sums of fixed capital by industry as the variables, but because of the unexpectedly large variation in the net gain coefficients in the region it was decided to use net rates of returns instead. The net gain and net rate coefficients are in any case closely correlated when calculated for the whole economy, and thus the latter is satisfactory for describing the profitability of industries (Tykkyläinen 1988: 351).

The LP model is applied to maximize the sum of net returns. The objective function of the LP model is:

$$
\text { (2) } \max z=a(1) x(1)+a(2) \times(2)+\ldots+a(48) \times(48) \text {, }
$$

in which $a(i)$ is the coefficient describing the profitability in industry $i$ (equation 1 ) and $x(i)$ is the variable, i.e. the total output of industry $i$.

The net returns $\mathrm{z}(\mathrm{i})$ for each industry are represented in the simulation model by

$$
\text { (3) } \quad z(i)=a(i) \times(i)
$$

The labour force, the key input variable in the simulation model, is taken here to consist of wageearners, salaried employees and owners, describing the number employed in each industry. The relation between total output $x(i)$ and labour force $q(i)$ is

$$
q(i)=t(i) x(i),
$$

in which $t(i)$ is labour force coefficient describing labour needed per total output. Since the labour force is used as an input variable for the user of the simulation model (Fig. 1), the total output has to be solved by

$$
x(i)=q(i) / t(i) .
$$


The following constraint is established for the labour force in the L.P model

$$
\mathfrak{t}(1) \times(1)+\mathfrak{t}(2) \times(2)+\ldots+\mathfrak{t}(48) \times(48)<=\ddot{a},
$$

in which ä is the maximum number employed in the region. Capital is equivalent to fixed capital and the capital requirements $p(i)$ of the industries are calculated in the simulation model as

$$
p(i)=c(i) x(i),
$$

in which c(i) is the capital coefficient describing the amount of capital needed per unit of total output. The maximum amount of capital in the economy described by the model is d, and the capital constraint in the LP model is thus

$$
\mathrm{c}(1) \times(1)+\mathrm{c}(2) \times(2)+\ldots+\mathrm{c}(48) \times(49)<=\mathrm{d} .
$$

The maximum output constraint in the LP model is set so that the maximum output of an industry cannot exceed the respective output at the national level, on the assumption that either the domestic market or restrictions inherent in the national economy will place some constraints upon production. Thus, denoting the total output of industry $i$ in the region by $x(i)$ and at the national level by $x$ '(i), one must have

$$
x(i)<=x^{\prime}(i) .
$$

The maximum output constraint in the simulation model is implemented in a manner in which the labour force input cannot exceed the amount of labour force for the whole country in industry $i$. Thus the upper limit of the number employed in each industry is

$$
q(i)=t(i) x^{\prime}(i) .
$$

Such limitations as the available natural resources, minimum volumes of output in given industries, limits upon use of water, pollution and power supply exist within the regional economy, but since these did not prove particularly significant for the results obtained with the LP model and simulation model in the preliminary analyses, they were not taken into account in the final models applied to Northern Karelia. They certainly could be relevant in other applications. Nevertheless, the equations (2), (6), (8) and (9) comprise the LP model in a conventional way (Taha 1982: 15-143; Wagner 1975: 29-126). The LP analysis was carried out using IMSLsoftware.

The total outputs of the power and water supply sectors are calculated in the simulation model in order to determine the infrastructural requirements of the production and household sectors. These figures can be used to some degree to evaluate environmental loading, but they are not very accurate because many resource processing sectors have their own power and water supplies and the price differences involved may be considerable. Even so, the figures do serve to represent production needs in the power and water supply sectors.

Power requirements in terms of purchases by the respective industries are:

$$
\text { (11) } x(s)=e(a)+e(t)+e(w) x(w)+e(s) x(s) \text {, }
$$

in which $x(s)$ is the total output of the power sector, e(a) the autonomous power requirement for agriculture, forestry, the service sector (SIC 1, 5-9) and household consumption, $\mathrm{e}(\mathrm{t})$ the total power requirement for the manufacturing industries and mining as a result of optimization or assessment, cf. equation (22). e(w) is the power requirement coefficient (i.e. power input per total output) in the water supply sector, e(s) is the respective coefficient in the power sector, and $x(w)$ is the total output of the water supply sector. Thus $\mathrm{e}(\mathrm{w}) \mathrm{x}(\mathrm{w})$ is the power requirement in the water supply sector, and $\mathrm{e}(\mathrm{s}) \mathrm{x}(\mathrm{s})$ the power requirement in the power industry itself (equation 11).

The water requirement, as total output $x(w)$ of the water supply sector, is obtained analogously from the equation

$$
\text { (12) } x(w)=v(a)+v(t)+v(s) x(s) \text {, }
$$

in which $\mathrm{v}(\mathrm{a})$ is the autonomous water requirement for agriculture, forestry, the service sector (SIC 1, 5-9) and household consumption, v(t) the total water requirement for the manufacturing industries and mining as a result of optimization or assessment, cf. equation (23). The coefficient $v(s)$ describes need of water in the power sector per unit of total output, and thus $\mathrm{v}(\mathrm{s}) \mathrm{x}(\mathrm{s})$ is the water requirement in the power sector. Water consumption in the water supply sector is nil. Thus the output of the power sector is expressed as (Tykkyläinen 1988: 407)

$$
\begin{aligned}
& x(s)=(e(a)+e(t)+e(w) v(a)+e(w) v(t)) /(1- \\
& e(w) v(s)-e(s))
\end{aligned}
$$

Once this total output figure has been obtained, the total output $x(s)$ of the power sector is inserted into equation (12), enabling the total output $x(w)$ in the water supply sector to be solved.

The variables e(a) and v(a) are supposed to have constant values and thus they can be omitted if the 
aim is to analyse the results in the manufacturing and mining industries only, but because of the aims and setting of the original study (Tykkyläinen 1988) it was relevant to take these additional sectors into account in the Northern Karelia study.

In order to obtain further information on the outcomes of the different economic alternatives, the simulation model contains linear equations for the individual branches of manufacturing, mining and power and water supplies (equations 14-21). Each variable is a function of total output determined by the coefficient, as
(14) $u(i)=n(i) x(i) \quad$ number of establishments
(15) $h(i)=k(i) x(i) \quad$ number of owners
(16) $m(i)=a ̊(i) x(i) \quad$ number of wage-earners
(17) $y(i)=l(i) x(i) \quad$ number of salaried employees
(18) $\mathrm{j}(\mathrm{i})=\mathrm{f}(\mathrm{i}) \mathrm{x}(\mathrm{i}) \quad$ wages
(19) $r(i)=g(i) x(i) \quad$ salaries
(20) $\mathrm{s}(\mathrm{i})=\mathrm{e}(\mathrm{i}) \times(\mathrm{i}) \quad$ power requirements
(21) $w(i)=v(i) x(i) \quad$ water requirements

The above equations are applied to the 50 branches of industry employed in the model.
The total power and water requirements in manufacturing and mining form the components of equations (11-13). These are calculated in the form

$$
\begin{aligned}
& \text { (22) } e(t)=e(1) x(1)+e(2) \times(2)+\ldots+e(48) \times(48) \\
& \text { (23) } v(t)=v(1) x(1)+v(2) x(2)+\ldots+v(48) x(48)
\end{aligned}
$$

Equations (12) and (13) give the total outputs of the water and power supply sectors. Using equations (3), (4), (7) and (14-19), the simulation model will indicate net returns, labour force, capital requirements, number of establishments, number of owners, number of wage-earners, number of salaried employees, wages and salaries by industries and the sums of these figures. Comparison with the basic year is performed by calculating the percentage differences between the model results and the basic year figures.

The coefficients in equations (4-23) are calculated from data applying to 1978 (SVT XVIII A: 99). The values for the coefficients a(i), e(i), v(i), t(i) and c(i) and the maximum output constraint $x^{\prime}$ (i) have been presented earlier (Tykkyläinen 1988: 411).

The evaluation model, i.e. the linear programming model together with the simulation model, is static and linear in character, properties which should be borne in mind when interpreting the results. In practice the coefficients are especially subject to change due to technological advances.
Fig. 2. Northern Karelia and the labour force employed in the manufacturing industries (SIC 2-4), by communes. Decreasing (shaded) and increasing (solid) manufacturing employment in 1978-86.

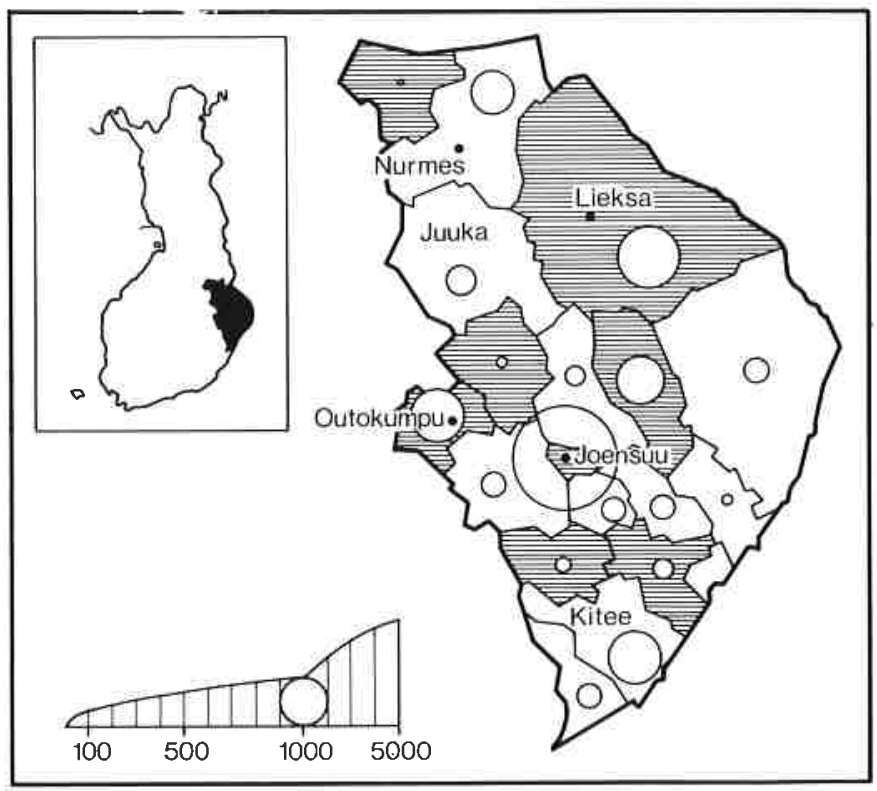




\section{The province of Northern Karelia}

Northern Karelia is the easternmost province of Finland and had 177288 inhabitants in December 1986, an average of 10 per sq $\mathrm{km}$ land area, accounting for $3.6 \%$ of the population of Finland as a whole (Fig. 2) (STV 1988). The province has suffered from severe problems of economic restructuring and unemployment since the mid-1960s, mainly because of the significant decline in primary sector employment. As a result of rationalization, migration reduced the population by $10.8 \%$ in $1960-70$ and $4.7 \%$ in 1970 - 80 , after which it remained virtually stable in $1980-86$, increasing by just $0.4 \%$ (STV 1962; 1971; 1988).

An expansion in industrial employment took place in the 1970s, when employment in manufacturing grew by $5.9 \% / \mathrm{yr}$ and the service sector also expanded. The labour force employed in manufacturing reached its peak in 1982, since which time a decrease in manufacturing employment has prevailed (Fig. 3). Meanwhile retrenchment in the primary sector has continued. Manufacturing employment has decreased by 1000 persons in $1980-85$, while the job loss in primary production over the same period has been about 3300 .

The capital city of the province is Joensuu, which has plywood and chipboard mills, for instances, but is mainly a service center for the province. The decrease in manufacturing from the base year 1978 on has been worst there in absolute terms, the job loss in manufacturing in 1978-86 having been 359 (Fig. 3). Outokumpu is an old mining community where 343 jobs have been lost mainly because of a cut-back in mining operations. Industrial work places have also decreased, by 111 and 100 respectively in the old-established wood-processing communities of Lieksa and Eno (adjacent to Lieksa). The most successful development has occurred in Kitee, where the increase in the number employed in manufacturing over the eight-year period was 343 . Manufacturing employment has also increased by 195 in Kiihtelysvaara, to the east of Joensuu, due to an active industrial policy and the proximity of the city, and by 170 in Juuka, where two soapstone companies have started up and expanded. The spatial changes in production reflect the restructuring of the old industrial base and the penetration of some new branches of manufacturing into the region.

The unemployment rate has been high during the 1980s and restructuring in primary sector and in manufacturing has caused problems (e.g. mining and saw mills, although some new factories have also had to close). Development planning has concentrated on claims for regional policy measures, and Northern Karelia now belongs to Development Zones I and II under the new Regional Policy Legislation.

The development planning goals for the province have changed somewhat over the last $10-15$ years. The goals in the latter half of the 1970s were to intensify regional policy measures, to work up local natural resources as far as possible, to develop process and labour-intensive industries and to attract state-owned enterprises (LAKS 1978: 4, 7, 34-36), whereas during the present decade the main focus has been on relieving structural prob-

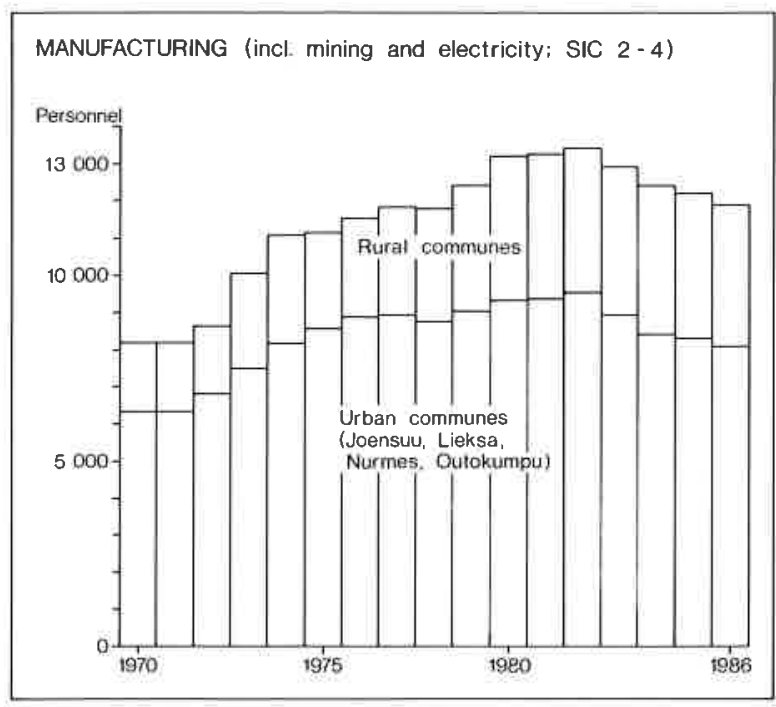

Fig. 3. Labour force in the manufacturing industries in $1970-1986$. 
lems in resource-based industries, diversifying the industrial base, increasing training and promoting the transfer of technology (LAKS 1985). Regional policy support has also been focused more on local entrepreneurship in order to stimulate the creation of small businesses. It was estimated in the early $1980 \mathrm{~s}$ that employment in manufacturing would continue to increase over the next 20 years but at a slower rate than earlier, and that jobs would be lost in agriculture (Table 1). The actual restructuring has been more rapid, however, with more jobs than expected being lost in agriculture and forestry while the manufacturing sector has not been able to expand to the extent predicted.

The employment target in the modelling experiment was designed according to the projections of the Council of State (Table 1) and taking into account the regional unemployment level. Subsequently these expectations of a growing demand for labour in manufacturing seem to have been overoptimistic, but this is not of any crucial significance as the evaluation is concerned with relative changes within the sector.

\section{Testing the model}

\section{Basic assumptions}

The basic year is 1978, when 11774 persons were employed in mining, manufacturing and power and water supplies in Northern Karelia, whereas 8900 persons were unemployed, 4100 of whom were seeking industrial or unclassified work. In the light based of the estimate of the growth in manufacturing published by the Council of State and the prevailing unemployment level, it is assumed that employment in manufacturing could be increased from below 12000 to 16000 , to correspond to 'full' industrial employment as of 1978. This goal seemed a reasonable one to be taken as a basis for planning in the early 1980 s.
The aims of research carried out at that time were to find the limits and preferred states of the regional economy, and thus the evaluation model was operated from these starting points to analyse the following six scenarios: A) a profitability-based scenario optimizing the regional economic output and structure according to the objective function, B) a resource-processing scenario maximizing local natural resource use, and 1)-4) assessment scenarios using questionnaires and analyses of these. The first two applications fulfil the aim of searching for the technical limits of restructuring, while the remainder represents the assessment approach and is based on the respondents' opinions on what would be the most desirable and efficient economic structure. Two groups are involved, students and businessmen, both containing nine members. The respondents' answers are combined into four scenarios using multivariate analysis.

The profitability-based scenario (A) relies on maximization of the total sum of net returns, equation (2). The basic year is 1978 . The capital stock is not expected to increase above the 1978 level, equation (8), and the maximum output cannot exceed the national level in 1978, equation (9). The total labour force employed in SIC 2-4 cannot exceed 16000 and the limit for the mining and manufacturing sectors was set at 15318 in equation (6) by iteration. The sum of those employed in sectors SIC 2-3 and 4 is thus 16000 in the final results.

The resource-processing scenario entails several assumptions. It is assumed that the output from mining will decrease to close to the national level and that about 200 persons will continue in the mining industry, which will conform to national profitability and technology standards. The heading 'other mining' covers both quarrying and peat extraction, and this sector employed about 200 persons in the early 1980s. It is assumed that such a level will be maintained and that the rate of profitability will remain up to national standards. Employ-

Table 1. Employment and labour supply in Northern Karelia 1960-1995 (1000 persons) (Council of State 1982).

\begin{tabular}{|c|c|c|c|c|c|c|}
\hline Year & $\begin{array}{l}\text { Agricul- } \\
\text { ture and } \\
\text { forestry }\end{array}$ & $\begin{array}{l}\text { Manu- } \\
\text { fac- } \\
\text { turing }\end{array}$ & Services & $\begin{array}{c}\text { Total } \\
\text { demand }\end{array}$ & $\begin{array}{c}\text { Supply of } \\
\text { labour }\end{array}$ & $\begin{array}{l}\text { Unemploy- } \\
\text { ment } \\
\text { rate }\end{array}$ \\
\hline 1960 & 54 & 6 & 29 & 89 & & \\
\hline 1970 & 31 & 8 & 36 & 75 & & \\
\hline 1980 & 17 & 14 & 40 & 71 & 77 & 7.6 \\
\hline 1985 & 15 & $15-16$ & $41-42$ & $71-73$ & $78-79$ & $9.0-7.6$ \\
\hline 1990 & $14-13$ & $16-17$ & $42-45$ & $72-75$ & $78-80$ & $7.7-6.3$ \\
\hline 1995 & $13-12$ & $16-18$ & $43-46$ & $72-76$ & $78-80$ & $7.7-5.0$ \\
\hline
\end{tabular}


ment in food processing is assumed to remain at the 1978 level of 1578 and profitability to be the same as the national average. The manufacture of wood products covers the sawmill industry and allied branches, and it is assumed in the model that virtually all the large-sized timber in the region will be used for this purpose. This implies an increase of about $52 \%$ in the local processing of such timber, which, taking profitability and technological standards to be of the same order as elsewhere in the country, would imply an employment of 3143 persons. The input of cordwood to the pulp and paper industry is assumed to be 2.1 mill. cubic meters, accounting for $95 \%$ of the cordwood available in the region. With production technology at the national level, employment would be 3636 persons. The sum of the outputs from the manufacture of wood products other than furniture and the manufacture of pulp and paper under this scenario would be $8.2 \%$ of the figure for the whole country and the labour force employed $7.6 \%$. This corresponds well to an annual permitted cut from the local forests amounting to $7.9 \%$ of the national total. The manufacture of mineral products in Northern Karelia consists mainly of supplies to local construction firms. It is assumed here that the level of production will remain at that recorded in 1978. The employment effect would be 402 persons, given existing conditions of profitability, technology and industrial mix.

Using these employment assumptions as inputs in the simulation model, the capital requirements increase above the 1978 level but the labour requirements remain below the target level, at only 9159 persons. The optimization model is then used to project full employment and add further industries to the region's economic structure. The number employed then increases to the level of 16000 , assuming the same capital-labour ratio for additional industries in the region as in 1978 .

The assessment was performed by setting two groups of experts the task of designing an ideal structure for the economy of Northern Karelia. They were asked what branches of industry should in their opinion be represented in the region in the mid1990s and what should be the size of each industry in terms of the number of employees. Selection could be made assuming a level of technology in each branch which was equivalent to that prevailing either nationally or in Northern Karelia. Each respondent answered separately, indicating an appraisal of employment in each of 48 branches of industry, up to an overall total of 15300 giving a final figure of approximately 16000 employed in SIC $2-4$ industries. This figure corresponds to the total employment constraint placed upon the scena- rio generated by the optimization.

The first group used in the assessment experiment comprised senior executives in business and administration, with a mean age of 34 and mainly an academic education, and the second group of advanced students of regional planning at the University of Joensuu. No very distinctive differences were found between the groups in the preliminary analysis, and the executive group even seemed to propose slightly more radical changes to the economy than the students.

The crude data provided by the replies from the two groups of informants were processed by principal component analysis and using a Varimax solution in order to obtain a typology for the structural changes proposed (Tykkyläinen 1988: 373-379; Harman 1968). The material for this analysis consisted of the employment figures put forward by the respondents for the various branches of industry (as denoted by the three-digit SIC codes). No distinction is made in this classification between national and regional levels of technology, so that each data item consists of the sum of the employment figures for the branches of industry carrying the same SIC code on both a national and a regional scale.

The replies are distributed fairly clearly into four groups. The groups indicated by the rotated principal component analysis, comprising replies gaining weightings greater than 0.5 , were formed into alternative economic structures by taking the mean employment figures for each branch of industry calculated from the original replies falling into respective groups. The resulting four alternatives, the assessments $1-4$, are then used as input data for the simulation model.

The proposals contained in the 18 answers were also treated as groups without mixing the answers of the persons belonging to the different groups as in the multivariate analysis. The economic structures proposed by the two groups are calculated as arithmetic means of the respondent's answers, designated STU (students) and BUS (businessmen). These group results are analyzed in connection with the testing of the predictive ability of the approach.

\section{Pre-scenarios tested}

Altogether six development scenarios were constructed based on the LP model results ( $A$ and $B$ ) and the assessments $(1-4)$, in addition to the mean answers for the groups (BUS, STU). Scenarios 2 4 are labelled according to the industries which increase their labour force most relative to the initial level. The hypothetical economic structures are: A) profitability-based, B) resource-processing, 1) restructuring, 2) metal and chemical products, 3) texti- 
les, clothing and metal products, 4) wood processing and chemicals, BUS) businessmen's group and STU) students' group.

The composition of the manufacturing industries as laid down in the six scenarios reaching into the 1990s and in real life in 1978 and 1986 are presented as sectors of a circle in Fig. 4, the growth propensities attached to each economic structure being calculated by reference to Kässi $(1982,21-79)$. The $\alpha$-values describe the numbers of employees required to move from one industry to another. If $q(i)$ is the number of employees in industry $i$ in the alternative in question and q'(i) the number in that industry in 1978, then

(24) $\alpha=\operatorname{sum} \operatorname{abs}(\mathrm{q}(\mathrm{i})-\mathrm{q}$ '(i))/ sum q'(i)

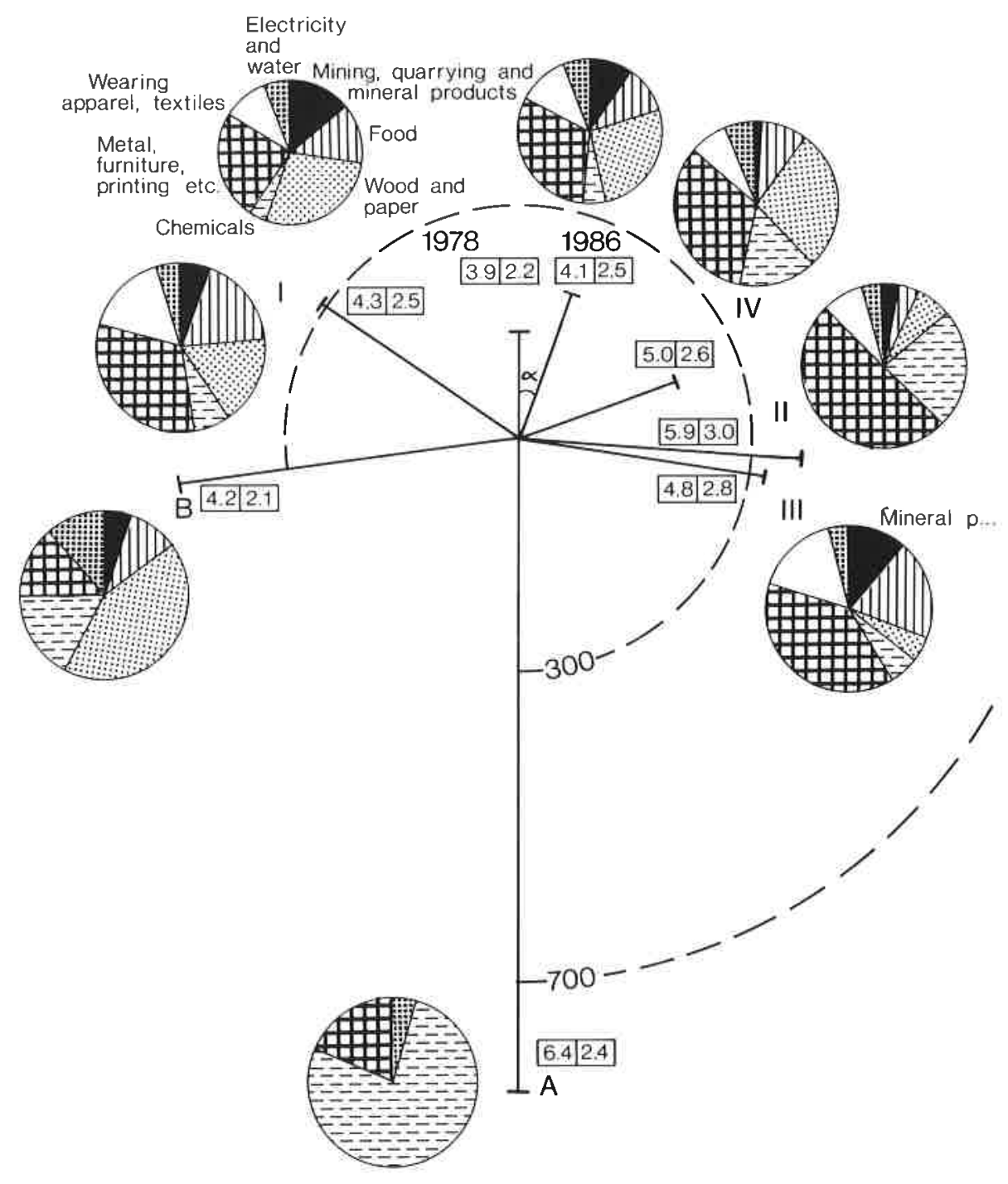

Fig. 4. Scenarios for Northern Karelia. The lengths of the lines denote the net returns in mill. FIM and the $\alpha$-values the deviations from the economic structure in 1978. Scenarios involving an increase in employment in resource processing industries are on the left and those involving an decrease in such employment on the right. The figures denote growth values for the scenarios according to rapid growth on the left and slow growth on the right. 
In the first scenario examined (A), the regional economy is reorganized on profitability criterion, equation (2), the capital invested is not expected to increase above the 1978 level, the number of employed is 16000 , including the power and water supply sector, and the total output in any single industry does not exceed the national level. The results show a very monostructured regional economy composed of chemical and allied industries and printing and publishing (Fig. 4). Net returns increase by $479 \%$ over the 1978 level, due to the inclusion of the most profitable industries in the model. The stability of the results is ascertained by calculating net returns coefficients for years of economic expansion $(1974,1978-9)$ and of recession (1975-77). The differences between the results of the expansion and the recession years and those of the ordinary profitability-based scenario in terms of the sums of the net returns are less than $5 \%$, and the industries chosen by the LP model belong to the light industries and are partly the same in each model run. Thus the profitability-based scenario is valid for different phases of economic fluctuation.

The resource-processing scenario (B) relies on the principle of increasing the output of resourcebased sectors as much as possible given the prevail- ing technology, as in the assumptions presented above. The most profitable industries were added to the model in order to achieve the employment goal. The net return is $211 \%$ higher than in 1978 , and the scenario is capital-intensive, requires an increased output from the power sector and raises salary and wage levels in the region (Fig. 5).

The development alternative $\mathrm{A}$ was created solely by the LP model and scenario B employed calculations of the maximum use of natural resources. They represent extreme or contrast scenarios (Hinloopen and Nijkamp 1984: 104). The assessment approach, on the other hand, generates more moderate results (Fig. 4 and 5), combining the goals of profitability and the heritage of a resource-oriented economic structure prevailing in Northern Karelia.

Most of the cases (50\%), and two-thirds of the students' replies in the assessment procedure, belonged to the first factor, a restructuring scenario, in which the change in the economic structure is smallest of any of the scenarios (Fig. 4). The focus of growth in production lies in metalworking, textiles and clothing, the processing of foodstuffs, sawn timber and the chemical industry, while outputs from the mining of ores and the manufacture of wood pulp are below the 1978 level. The industrial

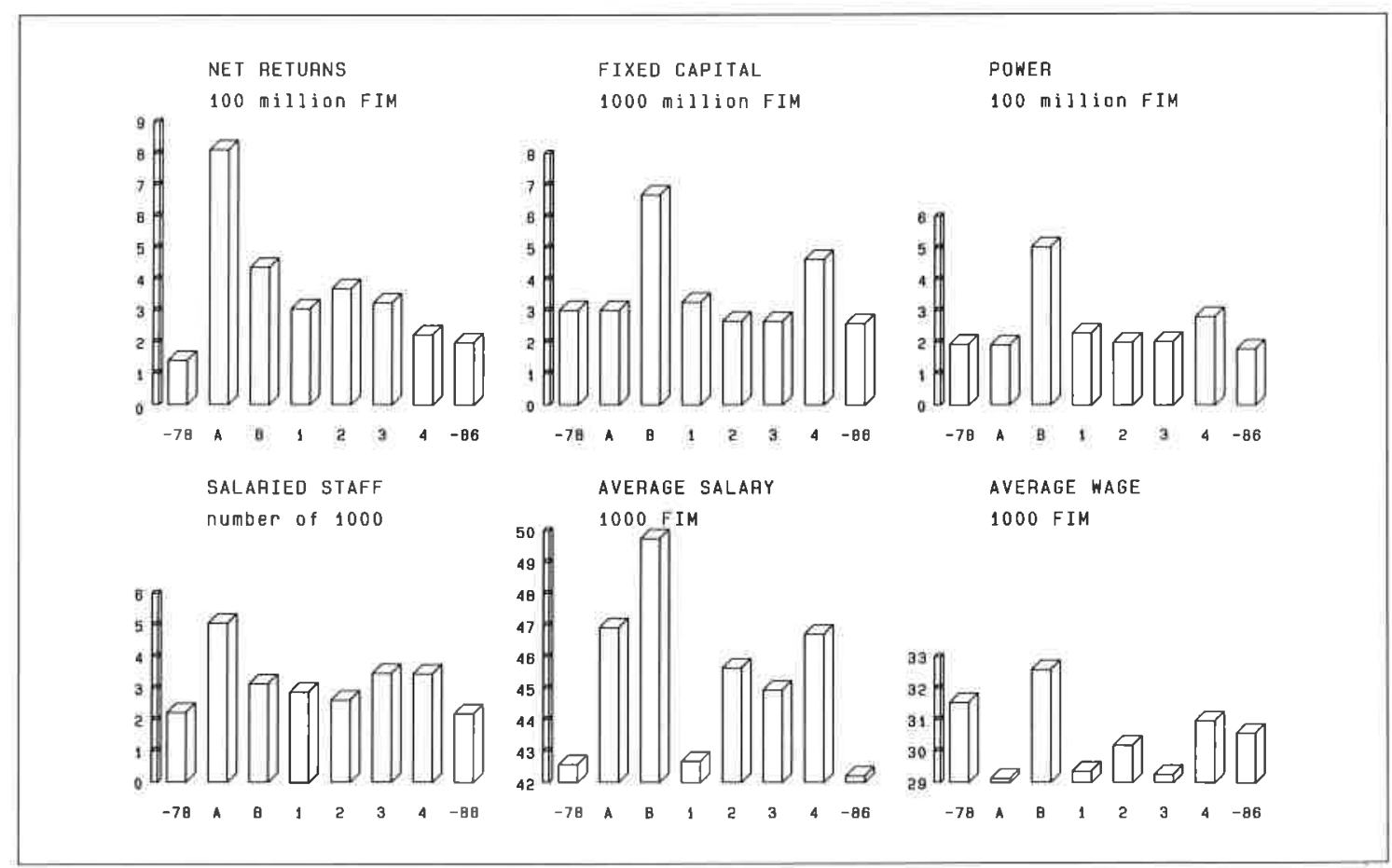

Fig. 5. Principal indicators of the scenarios. 
mix is less capital-intensive than in 1978 , but the sum of net returns is $117 \%$ higher. The economic structure of the region is steered in a more profitable direction, but it still devotes a higher proportion of its total employment to the resource-processing industries than do the other scenarios except for B.

In the second assessment scenario, metal and chemical products, a cut-back in production is envisaged throughout the resource-based sector with the exception of the manufacture of mineral products, and the sum of net returns is the highest of all the scenarios generated by assessment $(+163 \%)$. The scenario consists mainly of the metal-working and chemical industries increasing the numbers of salaried staff in particular (Fig. 4 and 5).

The third scenario, textiles, clothing and metal products, is composed of the typical 'new industries' promoted by Finnish regional policy in the 1970 s. It generates high net returns $(+131 \%)$ and entails the lowest capital requirement of all the scenarios considered, $-12 \%$ relative to the 1978 situation.

The wood processing and chemicals scenario presupposes a doubling in pulp production and a quadrupling in the chemical industry (Fig. 4). The latter is conceived of as being partly linked with wood processing and partly with the production of industrial chemicals. The largest single branch of the chemical industry would nevertheless be plastics. The sum of net returns under this scenario is lower than in the others considered here, but it still means a considerable improvement on the initial level (Fig. 5). This scenario operates very much along the lines proposed in the provincial development plans in the late $1970 \mathrm{~s}$, according to which the roundwood extracted from the forests in the region should be worked up within the region (LAKS 1978). The scenario falls short of this target as far as sawn timber is concerned, however, as the level of production allowed for would not suffice to consume all the sawlogs available locally, but exceeds the provisions of the existing permitted cut for cordwood by $10 \%$, so that pulp production on the scale envisaged here would involve either the import of timber or changes in processing techniques.

The sum of profits increases more than does employment in percentage terms in all the scenarios, and thus the tendency may be seen to be one of cutting back on production in less profitable industries. Scenario A is a highly monostructured and represents a fictive calculation, while scenario $B$ shows that the full use of local natural resources given the prevailing technology and production mix cannot solve the unemployment problem in Northern Karelia. The principles for allocating production in the assessments vary greatly, but the outcome is usually a diversification of the economy and an increase in profitability. The assessment contains notions of goals which take the form of maintaining the infrastructure, taking account the nature of the labour force, preserving the quality of the environment, processing the region's natural resources, diversifying production and forming processing chains, criteria which are frequently of greater importance than is profitability, since few of the replies appear to select their combinations of industries and levels of production exclusively on the grounds of profitability. The group of students in particular were well aware of the multiplier effects likely to be brought about by any changes in the structure of production, including the effects on profitability.

A dichotomy may be observed in the attitudes of the respondents towards developing the woodprocessing industry. Either pulp production should be substantially reduced or else the branch should be developed by changes in technology and by establishing links with the chemicals industry. Important areas for expansion, in the opinion of the respondents, would seem to be metal and chemical products. Substantiated arguments for growth in these industries are to be found mainly in the reserves of labour in Northern Karelia and the advantages offered under regional policy legislation.

The economy of Northern Karelia as it was in 1978 was operating at a low level of profitability as compared with what could be achieved under the conditions assumed by the present linear programming and assessments. A change in the direction of a more profitable structure of production would imply restructuring, the elimination of unprofitable functions and the development of production technology. These measures have been taken to some extent in subsequent years. Employment in the mining of ores has declined and a peat brickette factory which was running at a loss has been closed, major restructuring has taken place in the sawmills and large investment programs have been devised and implemented in the pulp and board industry. The evaluation model predicts problems in precisely these industries.

\section{Applicability of the evaluation model}

The applicability of the evaluation approach was studied by analyzing the ability of the model to anticipate actual economic restructuring and by analyzing temporal changes in the profitability coefficients. The following hypotheses are of importance from the point of view of the applicability of the model. Firstly, it is possible to predict future restructuring by means of the evaluation model on 
the basis of the profitability criterion, so that the evaluation procedure can to some degree predict the direction of restructuring. Secondly, if it is the case that the main coefficients of the model, the net rates of returns, change slowly in time, the results will also be valid in the longer run.

The goal of increasing employment in the manufacturing industries in Northern Karelia has not been reached, and the number employed in the manufacturing and allied industries (SIC 2-4) increased by only $1.4 \%$ in 1978 - 86, from 11774 to 11934 , due to growth in the first half of the period. It thus seems dubious at the moment, at least, to base the total labour estimate on the figures calculated by the Council of State. On the other hand, the relative changes in the industrial composition of the regional economy, not the absolute figures, are the essential ones when measuring restructuring, so that this miss-match in terms of employment levels is of minor importance.

Slow growth has had an effect on economic restructuring, however. Judging from experiences of growth in the 1970s, there might have been greater possibilities for major restructuring in the manufacturing industries if a stronger growth trend had prevailed. Obviously the structural renewal, especi-. ally in terms of new occupations, has been no more than moderate because of weak penetration by new industries. On the other hand, it is too early to evaluate the economic restructuring in full because the time span was set to extend into the latter half of the 1990 s, so that we are dealing only with a halfway result.

Growth in employment prevailed in 1978-86 in other mining (237) and other manufacturing industries (272), the manufacture of mineral products (89), metal products (366), and chemical industry (92), clothing (152), the supply of electricity and heating power (57) and the manufacture of wood products (165), while the main decreases were in metal ore mining ( -840 ), ironworking ( -20$)$, food production (-307), water supplies (-4) and pulp and paper production (-99). The figures in parentheses are absolute figures and numbers of employees, while the industries are ranked according to their percentage changes. These changes indicate that the profitability of the regional economy has increased.

Analysis by means of simulation model and insertion of the employment figures for 1986 into the model shows the increase in net returns summed over the industries to be $42 \%$ higher than the 1978 level with the original coefficients (1974-79). Assuming a fixed capital/labour force ratio in each industry, the sum of the capital requirements is $14 \%$ less than in 1978 and the economic structure has been directed more towards the low-salary, lowwage industries in terms of the results obtained with the original coefficients. It is assumed in this test that the technology used in the other mining (SIC 290) in Northern Karelia is that used nationally, in view of the radical restructuring of the industry since 1970s. This assumption does not alter the general interpretation of the results, even though it may tend to increase the predicted profits. Thus the structural transformation into 'new industries' and the trend towards a more profitable regional economic structure has continued.

We may set out to assess the similarities between the structures of the economy in 1978 and 1986 and the alternative structures generated by the evaluation model by examining the correlation coefficients (Table 2). The structure of the economy in each case is described by employment in each industry at the 2-digit level.

Scenarios 1-4, the groups and scenario B correlate better with the 1986 situation than with the 1978 situation, and the negative correlation in the case of the profitability-based scenario is reduced (Table 2). Thus the economic structure of the regional econo-

Table 2. Correlations between scenarios and the actual situation. Data are based on employment data by industries in Northern Karelia at the 2-digit level.

\begin{tabular}{llcc}
\hline & Scenario & $\mathrm{N}-\mathrm{K} 1986$ & $\mathrm{~N}-\mathrm{K} 1978$ \\
\hline 1$)$ & Restructuring & $.89^{* *}$ & $.83^{* *}$ \\
$2)$ & Metal, chemical pr. & .53 & .39 \\
$3)$ & Text, cloth., metal pr. & .62 & .54 \\
$4)$ & Wood pr., chemicals & $.75^{*}$ & $.68^{*}$ \\
A) & Profitability-based & -.15 & -.20 \\
B) & Resource-processing & .41 & .39 \\
BUS) & Businessmen & $.73^{*}$ & .60 \\
STU) & Students & $.82^{* *}$ & $.74^{*}$ \\
N-K 1978 & $.93^{* *}$ & 1.00 \\
\hline
\end{tabular}


my has evidently changed in the direction proposed in the scenarios. The best correlations with the economic structure in 1986 are achieved by the restructuring scenario, STU and BUS (i.e. the mean values for the groups), and also by the wood processing and chemicals scenario.

Multivariate analysis was used to rearrange the raw data into factors in order to find different types of sections existing in the raw data. The first factor, restructuring, representing moderate changes in the regional economic structure, includes the majority of the answers. The others thus represent 'atypical' answers, and succeeded in predicting the economic structure in 1986 less well than the majority of respondents. The lowest correlations were obtained by optimization results, as expected. Based on the assumptions laid down, the LP model seeks extreme solutions for the structural renewal of the regional economy, and thus the structure designed by the model remains far removed from the real situation.

The differences between the economic structure in 1986 and the structures of the scenarios, measured in terms of employment differences in the industries, are described in Figs. 6a and 6b. The restructuring scenario (RE1) markedly overestimates the number employed in food production and the manufacture of clothing, wood products and metal products. One reason for this is the higher level of manufacturing employment assumed in the economy, although this level as such does not affect the correlation, i.e. multiplying the employment figure in each industry by a constant has no effect on the correlations.

The over and under-estimations of the numbers

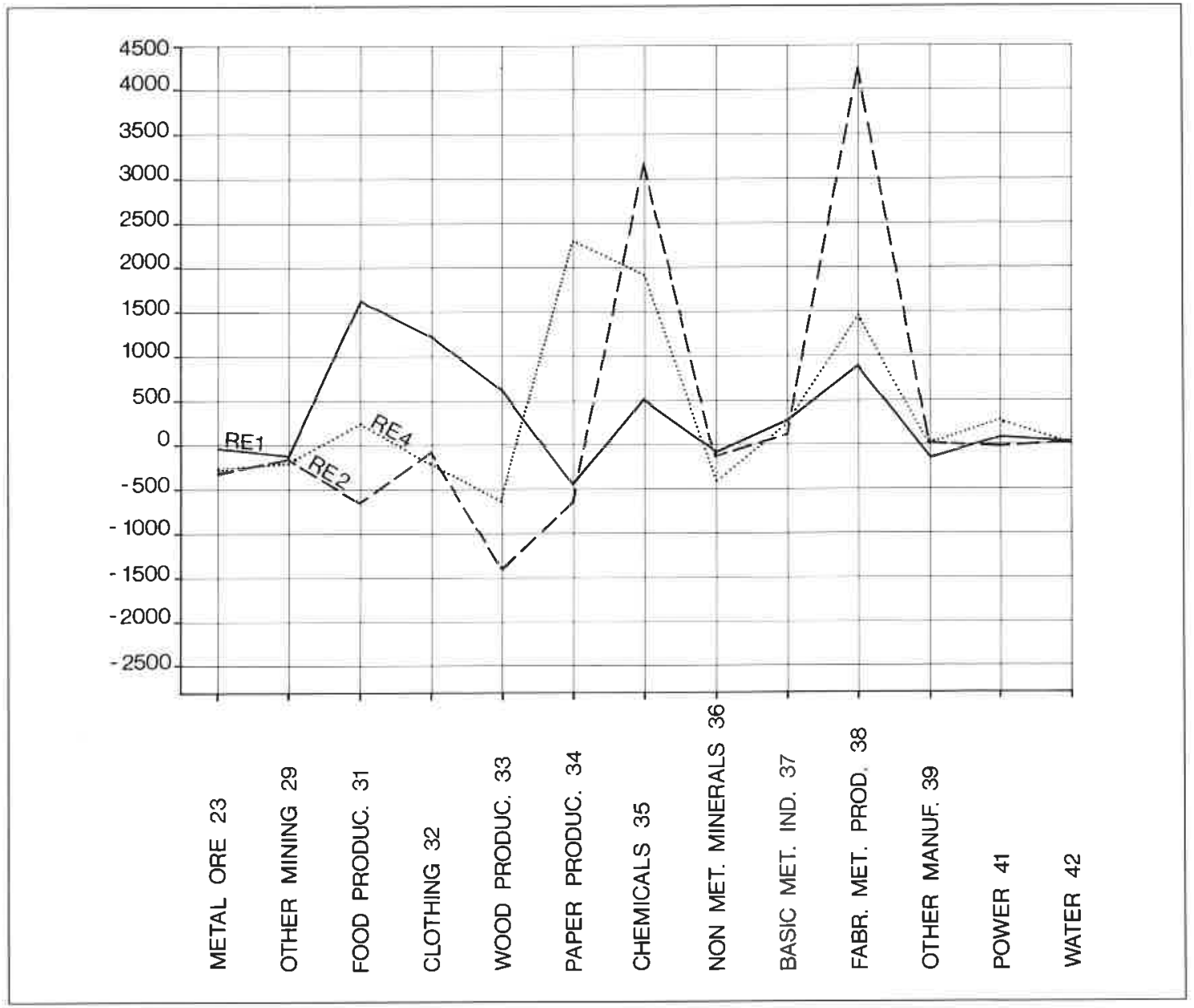

Fig. 6a. Deviations of the scenarios from the industrial employment figures of 1986 measured in terms of labour force. 


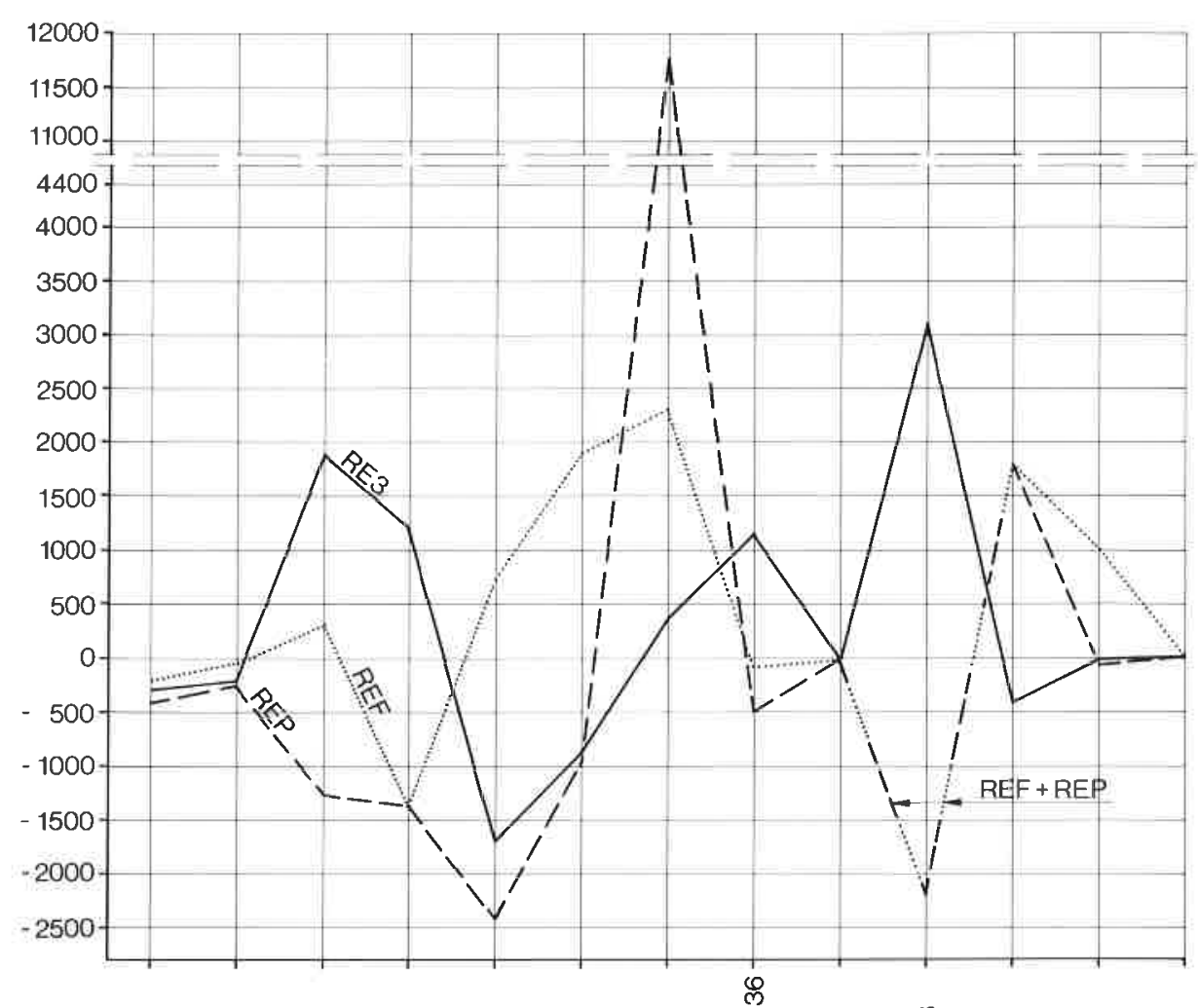

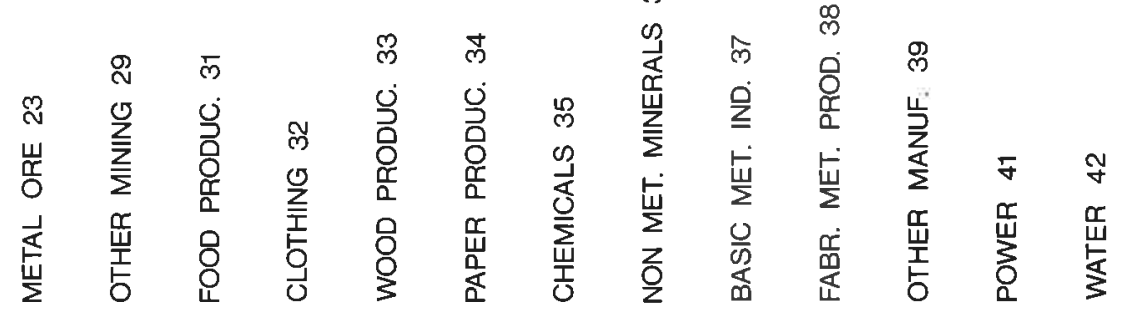

Fig. 6b. Deviations of the scenarios from the industrial employment figures of 1986 measured in terms of labour force.

employed vary more widely from one industry to another in the other scenarios, over-estimation being common in the case of the manufacture of metal products, as in the metal and chemical products (RE2), wood processing and chemicals (RE3) and textiles, clothing and metal products (RE4) scenarios. The profitability-based (REP) and resourceprocessing (REF) scenarios have common characteristics in that they under-estimate employment in some light industries due to the optimization procedure.

The goodness of fit of the scenarios was also measured by reference to the surplus and deficit of jobs in each industry as compared with the actual situation in 1986. Thus if the restructuring scenario had come about, there would have been 865 (7\%) less jobs in some industries in manufacturing (SIC 2 -4) than there actually were in 1986 , i.e. metal ore mining, other mining, manufacture of pulp and paper, manufacture of mineral products and other manufacturing (Table 3; column B). The surplus of jobs would have been 5048 (42\%) compared with the 1986 level. The total changes in job surplus and deficit is the sum of these percentages, e.g. $50 \%$ in the case of the restructuring scenario. Measured in this way, the restructuring scenario resembles the 
minor changes advocated by the students, businessmen and scenario 4. A hypothetical 'return' to the 1978 level is calculated in the second last row (table 3; column B), showing that there would have been reduction in employment by $12 \%$ in the actual growth sectors in the 1980 s, i.e. the manufacture of metal products, other manufacturing, other mining, manufacture of wood products, clothing industry, chemical indrustry, mineral products and the supply of electricity and heating (Table 3; column B). The surplus of jobs $(11 \%)$ is of course smaller than the deficit because of the smaller number of jobs in 1978 than in 1986, which also means that the 'return' case is not comparable with the scenarios, where the total number of jobs in each case is about 16000 .

The changes in employment are smallest in the restructuring scenario, but if the goodness of fit is measured by the correlation between the actual differences in 1978-86 and the differences in the scenarios relative to the 1978 level, the mean for the businessmen and the second scenario show the highest correlations (Table 3; column D). The restructuring represented by these alternatives is more similar to the actual changes than those generated by the restructuring scenario, but the employment residuals of all the scenarios with respect to the 1986 employment level are large, reflecting 'overprediction' of the changes. Thus if the restructuring continues according to the recent trends, he goodness of fit measured by employment changes will also increase the validity of the businessmen's mean answer and of the second scenario as future structures for the regional economy.

Theoretically, the most profitable alternative should provide a prototype for development. Most of the figures used in the analysis describing the profitability-based scenario represent total dissolution of the major sectors of the regional economy according to the 1978 employment figures, the few remaining ones being subject to immense growth. Such a pattern is inappropriate for describing a gradual transition of the economy towards greater profitability, and a low correlation is to be expected. Even the scenarios themselves differ considerably from each other, the conclusion being in each case that the range of possible outcomes is quite narrow. There exists no 'reverse' economic structure in the assessment treated by multivariate analysis or the calculations of means. The single negative correlation in Table 2 indicates that only the LP model generates such a reverse structure, the profitabilitybased scenario, a highly one-sided one consisting of the few most profitable industries. It is a common characteristic for the scenarios to emphasize those light industries which actually did increase the labour force in the 1980s.

In the short run, after eight years, the moderate proposals for restructuring presented by the students coincided well with the actual structure of the Northern Karelian economy in 1986. The businessmen's answers, which succeeded well in predicting the direction of the changes, were more radical and represented a marked decrease in employment in such industries as mining, food production and sawmills. Pulp and paper production is expected to increase its labour force, contrary to the students' answers, the plans being likely to by fulfilled in Eno in the 1990s. The businessmen's proposed increase in certain growth sectors is larger than that allowed for by the students. Comparison of the results achieved by the businessmen with the expectations regarding restructuring also suggests that it is

Table 3. Sums of the employment surpluses (A) and deficits (B) in the various industries in percentages compared with the economic structure prevailing in 1986, sums of the changes $(C=A+B)$ compared with the 1986 level and correlations between changes in employment in 1978 - 86 and changes presented by the scenarios relative to the employment level in 1978 (D).

\begin{tabular}{llrrrr}
\hline & Scenario & (A) & (B) & (C) & (D) \\
\hline 1$)$ & Restructuring & 42 & 7 & 50 & .48 \\
$2)$ & Metal, chemical pr. & 63 & 29 & 91 & .50 \\
$3)$ & Text., cloth., metal pr. & 64 & 30 & 95 & .38 \\
$4)$ & Wood pr., chemicals & 52 & 16 & 68 & .39 \\
A) & Profitability-based & 114 & 80 & 193 & .15 \\
B) & Resource-processing & 67 & 33 & 100 & .17 \\
BUS) & Businessmen & 47 & 13 & 60 & .56 \\
STU) & Students & 46 & 11 & 58 & .49 \\
N-K 1978 & 11 & 12 & 23 & $*$ \\
N-K (1986-1978) & $*$ & $*$ & 1.00 \\
\hline
\end{tabular}

\footnotetext{
* Category not applicable
} 
reasonable to expect the businessmen's mean to be increasingly more valid as the original time schedule of $10-15$ years near its end.

As expected, the multivariate analysis arranges the answers in unequal groups with one scenario succeeding well in predicting the economic structure that prevailed in 1986 and representing the majority opinion of the respondents. The LP model generates only hypothetical but not probable economic structures, which are unsuitable for prediction but may generate some sort of framework of ideas for development planning. The optimization procedure is thus of value in searching for boundaries, but assessment seems to be a more appropriate approach, since it sets out from the context of past industrial structure and reflects gradual changes in this.

Three qualifications conceming the aims adopted in the evaluation design phase must be taken into account when considering the results. Firstly, the task of the respondents in the assessment was to design an efficient, ideal economic structure for Northern Karelia, assuming the role of regional economic planners. Thus the goodness of fit in forecasting as evaluated at the present moment is only of secondary importance as far as the evaluation design phase is concerned (Tykkyläinen 1988). If the major aim had been to predict the most probable structure of the economy, the answers would have been more similar and closer to reality. Secondly, the time horizon was longer in the evaluation procedure than it is possible to cover in this paper. Thirdly, the aim of the LP model analyses was to find the range of different solutions for industrial structures based on resource processing and the most profitable industries. The multivariate analysis served a 'group-seeking' purpose in the assessment. If the task had been a predictive one, the LP model would have been applied using more realistic assumptions than were made here, and the multivariate analysis would have probably been employed in a different manner. On the other hand, the viewpoint would also have been more restricted and thus the idea of measuring the range of possible outcomes achievable by LP modelling and assessment would have been lost and little material would have been generated for comparison. Improbable results of this kind are also needed in regional development planning, e.g. to lend more definition to our fictions and to enable them to be evaluated more precisely.

\section{Changes in coefficients}

The values for the net rate of returns are calculated based on data taken from the Industrial Statistics, and such measures are commonly used as indicators of profitability (e.g. Airaksinen 1978). Research shows that differences in profitability between industries are quite large in Finland and are sustained even in the longer run, while the cyclical element is strong in Finnish economy because of sharp variations in the prices of staple products. Nevertheless, the restructuring of the economy does support the theory that rates of profitability in industry will converge, but very slowly.

Some tests based on the data available can be performed to evaluate the profitability differences in the Finnish economy from the viewpoint of individual companies. Profitability indicators based on company accounts are available by industries for the 1980 s and photocopies of the data at the 3-digit SIC level were obtained (Financial ... 1989). The large multi-industry companies which dominate the Finnish economy are inserted as such into each industry class in the statistics according to their main activity. As expected the variation in profitability is smaller than in the former, industry-based indicators, due to the mixed structure of production. The correlations between the indicators based on company and national accounting are low, e.g. that between gross margin as a percentage of turnover and net rates of return is only .32 at the 3-digit level in 1985 even though these indicators measure similar things. Thus if the data base had been drawn from company accounts the results would have been not so dramatic. On the other hand, a measure based on multibranch data is not valid for expressing profitability in individual industries.

Exact comparison with other studies of profitability is not possible because of the differences in industrial classification. According to a rough comparison, low profitability is to be found in pulp and paper production, for example, and the power sector was among the ten least profitable industries at the four-digit level in 1974-82 (Virtanen 1987). The most profitable industries are certain subbranches of the other manufacturing industries (SIC 390). The manufacturing of wood products, pulp and paper and the basic metal industries also seem to represent industries of lower than average profitability in the longer run 1960-81 (YläAnttila 1985). The low profit rate in the paper industry is also noted by Artto (1985) for the period $1970-81$, and the results in other industrial sectors presented by Artto (1987) are to great extent similar to those of other studies referred to here. Furthermore an input-output study performed in 1985 showed that a negative profit was to be found in the manufacture of wood products, in electricity, gas and water supplies, and in the basic metal industries. The most profitable industries were the 
manufacture of beverages and tobacco products and 'other manufacturing' (Input-output ... 1988: 1011). The extreme differences are thus analogous to those found here in spite of variations in the time period and in details of the computation. Thus the values of the net rate of returns are to a great extent similar to the values of the profitability estimates obtained elsewhere. At the time of writing this in 1989 , many industries, notably those processing the natural resource base, are making good profits compared with the trend, but this does not detract from the low profits associated with staple production in the longer run, which lead to the restructuring of a resource-based economy to obtain a more diversified one. Diversification of this kind has taken place throughout Finland in recent decades (see Hjerppe 1988; Palo 1988) and has proceeded rapidly in Northern Karelia since the late 1960s (Tykkyläinen 1988).
The stability of the profitability indicators affects the validity of the result when used to evaluate the long-term economic structure, and also determines how often the coefficients should be updated.

Firstly, the mean values of the net rates of returns for the years 1974-1979 (i.e. the original coefficients in the model) correlate with the values for 1985 (Fig. 7). This confirms the validity of the use of the model at least for the year 1985. Time stability is analyzed here in detail for the three different profitability indicators applying to Northern Karelia and the whole country according to the industrial classification obtained in the model. Two years of moderate growth, 1984 and 1985, are used to test whether the results would have been different if the evaluation had been made in 1984-85. The Gross domestic product increased by $3.3 \%$ in the former year and by $3.5 \%$ in the latter. The other mining industries (SIC 290) in Northern Karelia are omitted

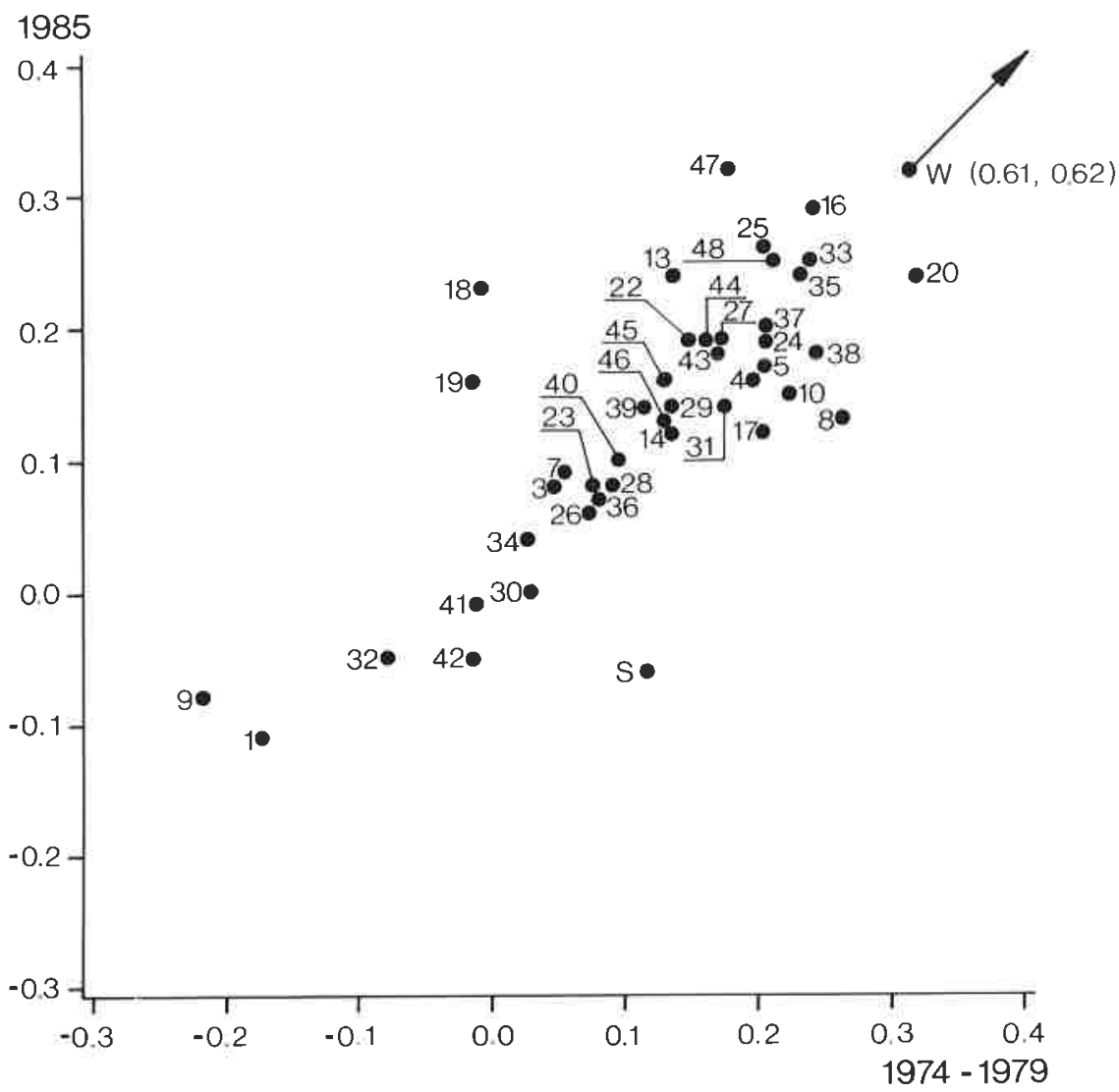

Fig. 7. Net rates of returns, by industries, in $1974-1979$ and 1985 in the evaluation model. 
from the model because their internal composition has changed markedly since the 1970 s, from predominantly peat extraction and processing to a focus on the soapstone industry. Also, confidentiality requirements prevent one from quoting profitability estimates for all the remaining 49 industries (including power and water supplies) and thus the maximum numbers of observations vary between 43 and 45 in the correlation table (Table 4).

The variables in Table 4 are the net rates of returns as expressed by equation (1). Gross rates are calculated omitting the depreciations mentioned in equation (1), and net gains for fixed capital are calculated by dividing the numerator in equation (1) by total amount of fixed capital (i.e. the sum of the value of buildings, machinery and vehicles).

The net rates of returns alter fairly slowly (Table 4), which supports the hypothesis that profitability differences change slowly and lead us to the conclusion that the results given by the model are still quite valid in the 1980s.

The correlation is higher in the whole country than in Northern Karelia, as is to be expected since the smaller the area is the bigger the random variation will be. The fact that the net and gross rates correlate quite closely indicates that depreciation is not of any decisive significance for profitability, and also detracts from the argument of possible overvaluation of this depreciation. The net gain for fixed capital correlates markedly with other measures of profitability, and it can thus be concluded that the measure used is valid and the results are quite stable even in the context of a time period of at least ten years. This also leads us to the conclusion that the results would not deviate very much even if newer coefficients had been used with respect to profitability. In this context the results seem feasible over a period longer than a few years.

\section{Conclusions}

The model as presented here is clearly superficial, especially concerning technological changes and productivity, but it is still evident that a fairly simple model can produce a considerable amount of information for development planning, and if interpreted in a manner that takes account of the restrictions attached to it, can open new perspectives on regional development planning.

The evaluation model experiment indicates that the economic structure of Northern Karelia is undergoing restructuring into a more profitable state, which was the main recommendation of the evaluation approach. Most members of the groups pointed out the necessity for restructuring more than did the official Regional Development Plan designed by the provincial authorities and this path also seems to be more probable, at least according to the trend that prevailed in the $1980 \mathrm{~s}$.

One may be sceptical about the results because of the short periods of time elapsing between the experiment, the year 1986 and the base year. In the experimental situation data concerning employment could have been received for year 1980, but it was not supplied to the respondents, and secondly, the goals of the Regional Development Plan for the province pointed out the possibilities associated

Table 4. Correlations between net rates of return, gross rates of return and net gains for fixed capital.

\begin{tabular}{|c|c|c|c|c|c|}
\hline & 1984 & $\begin{array}{c}\text { Net rate of return } \\
1985\end{array}$ & $1984 \quad 85$ & $\begin{array}{c}\text { Gross rate } \\
1985\end{array}$ & $\begin{array}{c}\text { Net gain } \\
1985\end{array}$ \\
\hline $\begin{array}{l}\text { Net rate of return } \\
\text { All observations }\end{array}$ & & & & & \\
\hline $1974-79$ & .76 & .85 & .80 & .63 & .70 \\
\hline $\begin{array}{l}\text { Northern Karelia } \\
1974-79\end{array}$ & .71 & .82 & .76 & .60 & .74 \\
\hline $\begin{array}{l}\text { Whole country } \\
1974-79\end{array}$ & .87 & .92 & .91 & .75 & 65 \\
\hline $\begin{array}{l}\text { Net rate of returns } \\
\text { All observations }\end{array}$ & & & & & \\
\hline $\begin{array}{l}1985 \\
\text { Northern Karelia } \\
1985\end{array}$ & .93 & 1.00 & .98 & .77 & .82 \\
\hline $\begin{array}{l}\text { Whole country } \\
1985\end{array}$ & .94 & 1.00 & .98 & .77 & .81 \\
\hline
\end{tabular}


with the local natural resource base, in conformity with the spirit of the time. In this context the restructuring and its direction could not be said to have been self-evident facts at the time, as was also shown in some of the answers and scenarios, which increase natural resource use. The majority of the respondents predicted the most probable path of development, and others scenarios which came true to lesser extents.

The evaluation model used hcrc, cven when applied in this scenario manner, can predict future development and gains its best fit when combined with assessment, at least in the short run. The optimization approach has very little to do with actual development, even though it can be very fruitful for identifying the constraints on development. In the present case it showed the limits of the expansion possibilities for extensive resource processing. The changes in economic structure follow profitability, but slowly.

The profitability parameters change slowly and thus the result seems to be stable at times of moderate growth. The corollary is that the model is valid in the medium run, at least at this stage. Sudden changes can of course alter the ranking of industries in terms of profitability, so that it was not yet possible to analyze the effects of the drop in oil prices in 1986, for example. Only two years, 1984 and 1985, were used for comparison, but other results also indicate the stability of differences in profitability, even though it should be remembered that boom years in particular may cause deviations in profitability rankings.

Nevertheless, the interdependence between restructuring and profitability differences is distinct at the regional and the national level, and the coefficients are stable enough to succeed in indicating the direction of restructuring.

\section{REFERENCES}

Airaksinen, Timo (1978). Tutkimus kannattavuuden mittaamisesta ja komponoinnista. Teollistamisrahasto B 1, Helsinki. 95 pp.

Artto, Eero (1985). Paperiteollisuuden kansainälinen kilpailukyky. 184 pp. Artto-Analyses, Helsinki.

Artto, Eero (1987). Teollisuuden kilpailukyky 1974 1984. Suomi-Ruotsi. Yhteenvetoraportti. The Helsinki School of Economics, Laskentatoimen laitos 14, Helsinki. 157 pp.

Council of State (1982). Lääneittäinen väestö- ja työpaikkasuunnite vuosille 1985,1990 ja 1995 . Valtioneuvoston kanslian julkaisuja 1982: 3, Helsinki. 56 pp. + app.

Financial Statements Statistics of Industrial Enterprises 1985 (1989). Central Statistical Office of Finland. Enterprises, Helsinki, Mimeo.
Hinloopen, Edwin and Peter Nijkamp (1984). Information Systems and Uncertainty in Planning. In P. Nijkamp and P. Rietveld (eds.): Information Systems for Integrated Regional Planining, 101-119. Elsevier, Amsterdam.

Harman, Harry H. (1968). Modern Factor Analysis. 2nd revised edition. 474 pp. University of Chicago Press, Chicago.

Hjerppe, Riitta (1988). Suomen talous 1860-1985. Suomen Pankki, Kasututkimuksia XIII, Helsinki. 314 pp.

Input-output 1985 (1988). Central Statistical Office of Finland. National accounts 1988: 1, Helsinki. 46 pp.

Kässi, Tuomo (1982). Teollisuus 1990. The Research Institute of the Fimnish Economy B 34, Helsinki. 164 pp.

LAKS (1978). Pohjois-Karjalan läänin alıeellinen kehitränissumnnitelma. (Regional Dev'elopment Plan for Northern Karelia). 126 pp. Pohjois-Karjalan lääninhallitus, Joensuu.

LAKS (1985). Pohjois-Karjalaa kehittämään. Läänin tavoitesummitelma vuosille 1985-2000. (Regional Development Plan for Northern Karelia, 1985-2000. Targets). 91 pp. Pohjois-Karjalan lääninhallitus, Joensuu.

Palo, Matti (1988). Forest-based development theory revisited with a case study of Finland and prospects for developing countries. In Palo, M. and J. Salmi: Deforestation or Development in the Third World? Vol II, 13-157. The Fimmish Forest Research Institute, Division of Social Economics of Forestry 309, Helsinki.

Snickars, Folke, Åke E. Andersson and Murat Albegov (1982). Regional Development Modeling - Theory and Practice. In Albegov, m.. Å. E. Andersson and F. Snickars (eds.): Regional Developmen Modeling: Theory and Practice, 3-25. North-Holland, Amsterdam.

STV = Statistical Yearbook of Finland. Central Statistical Office of Finland, Helsinki.

SVT $=$ Suomen virallinen tilasto (Official Statistics of Finland). Central Statistical Office of Finland, Helsinki.

Taha, Hamdy A. (1982). Operations Research. An Introduction. 3rd edition. $848 \mathrm{pp}$. Macmillan Publishing Co., New York.

Tykkyläinen, Markku (1988). Periphery syndrome - a reinterpretation of regional development theory in a resource periphery. Fennia 166, 295-411.

Virtanen, Visa (1987). Toimialoittaisten kannattavuuserojen selittäminen rakenne-kannattavuushypoteesilla. Jyyäskylän yliopisto, Taloustieteen laitos 73, Jyväskylä. 123 pp. + app.

Wagner, Harvey M. (1975). Principles of Management Science. With Applications to Executive Decisions. 2nd edition. 612 pp. Prentice-Hall, Englewood Cliffs, New Jersey.

Ylä-Anttila, Pekka (1985). Kannattavuuserojen sopeutuminen Suomen teollisuudessa. Adjustment of Profitability Differences in Finnish Economy. English Summary. The Research Institufe of the Fimnish Economy' C 38, Helsinki. 119 pp. 